\title{
EEG gamma-band synchronization in visual coding from childhood to old age: Evidence from evoked power and inter-trial phase locking
}

\author{
Markus Werkle-Bergner*, Yee Lee Shing, Viktor Müller, Shu-Chen Li, Ulman Lindenberger \\ Max Planck Institute for Human Development, Center for Lifespan Psychology, Berlin, Germany
}

\section{A R T I C L E I N F O}

Article history:

Accepted 21 April 2009

Available online 23 May 2009

\section{Keywords:}

Lifespan development

EEG oscillations

Gamma

Sensory coding

Differentiation/dedifferentiation

\begin{abstract}
A B S T R A C T
Objective: To investigate lifespan age differences in neuronal mechanisms of visual coding in the context of perceptual discrimination.

Methods: We recorded EEG from 17 children (10-12 years), 16 younger adults (20-26 years), and 17 older adults (70-76 years) during a simple choice-reaction task requiring discrimination of squares and circles of different sizes. We examined age-group differences in the effect of stimulus size on early ERP components, evoked gamma-band power, and inter-trial phase-stability in the gamma band as assessed by the phase-locking index $(P L I)$.

Results: In the absence of age differences in discrimination accuracy, we observed reliable age differences in patterns of ERP, evoked gamma power, and PLI. P1 and N1 peak amplitudes were larger and the peak latencies longer in children than in adults. Children also showed lower levels of evoked power and PLI than adults. Older adults showed smaller increments in evoked power with increasing stimulus size than younger adults, but similar amounts of phase locking for small- and medium-sized stimuli as younger adults.

Conclusions: The relative importance of different coding mechanisms in early visual areas changes from childhood to old age. Due to synaptic overproduction and immature myelination, the visual system of children is less entrained by incoming information, resulting in less synchronized neuronal responses. Adults primarily rely on sparse representations formed through experience-dependent temporally synchronized neuronal interactions. In old age, senescent decline in neuronal density and neurotransmitter availability further increase the reliance on temporally synchronized processing.

Significance: Findings from this study defy the notion that sensory aging consists in a reversal of sensory development in childhood, and point to a high degree of age specificity in mechanisms of visual coding. (C) 2009 International Federation of Clinical Neurophysiology. Published by Elsevier Ireland Ltd. All rights
\end{abstract} reserved.

\section{Introduction}

During child development and aging, the structure and function of the human brain undergo major changes (Sowell et al., 2003; Raz et al., 2005; for reviews, see Baltes et al., 2006; Cabeza et al., 2005; Li, 2003; Lindenberger et al., 2006). Results from post-mortem studies of the brain, magnetic resonance imaging (MRI), functional MRI, as well as electrophysiological studies indicate that human brain development can be characterized as non-linear and heterochronous, with different parts of the brain follow different developmental time courses (Gogtay et al., 2004; Sowell et al., 2003; Thatcher, 1992; Thatcher et al., 1986). Besides lifespan changes in brain structure and connectivity, the availability and

\footnotetext{
* Corresponding author. Address: Max Planck Institute for Human Development, Center for Lifespan Psychology, Lentzeallee 94, 14195 Berlin, Germany. Tel.: +49 3082406447.

E-mail address: werkle@mpib-berlin.mpg.de (M. Werkle-Bergner).
}

expression of neurotransmitters (especially dopamine) also changes and affects cognitive functioning (for reviews, see Backman et al., 2006; Li et al., 2006).

Hence, a major challenge for developmental cognitive neuroscience is to understand how changes in cognitive functions related to maturation and senescence are related to lifespan changes in the neuronal information processing architecture (see, Lindenberger et al., 2006). Recent behavioral and physiological evidence suggests that interactions between maturation and learning from childhood to adulthood lead to increasing cortical differentiation and integration (Johnson, 2001; Nelson and Luciana, 2001; Thatcher, 1992) that is accompanied by more refined intellectual ability structures (Garrett, 1946; Li et al., 2004). Senescent changes from adulthood to old age, on the other hand, result in dedifferentiation and reduced cortical specialization of functional circuitry (Park et al., 2004; see also Reuter-Lorenz and Lustig, 2005 for review) that are accompanied by dedifferentiated cognitive and sensorimotor functions (Baltes and Linden- 
berger, 1997; Li et al., 2004). However, surprisingly little is known about lifespan changes in neuronal mechanisms that code sensory events during visual perception. Therefore, in the present study, we examine lifespan age differences in neuronal synchronization as indexed by oscillations in the gamma-frequency range $(>30 \mathrm{~Hz})$ during a visual choice-reaction task in children, younger adults, and older adults.

The visual system is characterized by multiple parallel channels of functional specialization and hierarchical organization. Thus, the information about complex objects must be processed by many different neuronal assemblies in distinct brain areas (Felleman and Van Essen, 1991; Tobimatsu and Celesia, 2006). However, our visual experiences of the environment are integrated percepts despite the spatial segregation of visual processing in the brain. This observation calls for a neuronal mechanism, often referred to as binding (Treisman, 1999; Treisman and Gelade, 1980; Zimmer et al., 2006), allowing for integration of distributed information in the service of cognitive functions (e.g., Ballard et al., 1983; Barlow, 1972; Von der Malsburg, 1981). Several authors suggested that such a mechanism could be implemented in the brain via temporally synchronized firing patterns of neuronal assemblies (Engel et al., 1992; Engel and Singer, 2001; Fries, 2005; Jensen, 2006; Lisman, 2005; Singer and Gray, 1995; Singer et al., 1996). Although not undisputed (e.g., Palanca and DeAngelis, 2005; Shadlen and Movshon, 1999), the binding theory has received support from studies of intracranial recordings that revealed that groups of activated neurons tend to synchronize in the gamma-frequency band $(30-100 \mathrm{~Hz})$. Gamma-band synchronization has been linked to several cognitive functions in a range of studies (see Engel et al., 1992, 2001; Herrmann et al., 2004; Singer and Gray, 1995; Tallon-Baudry, 2003; Tallon-Baudry and Bertrand, 1999 for reviews). Furthermore, it has been shown that the precise timing of pre- and post-synaptic activation determines long-term changes in synaptic strength (Bi and Poo, 1998; Markram et al., 1997) and that synchronization of synaptic inputs in the gamma band directly enhances their effective synaptic strength (König et al., 1996; Salinas and Sejnowski, 2001). Regardless of the exact roles of gamma oscillations in cognitive functioning (cf. Herrmann et al., 2004; Singer and Gray, 1995; Tallon-Baudry and Bertrand, 1999, for reviews), it becomes obvious that synchronized oscillatory activity can be considered an effective and flexible communication structure on top of the less plastic anatomical structure (Fries, 2005). However, not much is known about how lifespan changes in neuroanatomy and neurochemistry during maturation, learning, and senescence affect local synchronization properties as evidenced by EEG gamma-band oscillations (cf. Böttger et al., 2002; Csibra et al., 2000; Yordanova et al., 2000, 2002, for examples the of the few gamma-band studies with developmental or aging samples).

Therefore, the current study adopts a lifespan perspective (Baltes et al., 1977, 1999; Craik and Bialystok, 2006), which assumes that development at neuronal and cognitive levels proceeds through interacting influences of maturation, past experience, learning, and senescence (Baltes et al., 2006; Lindenberger et al., 2007). A direct comparison of children, younger, and older adults while performing simple visual discrimination would provide the opportunity for uncovering mechanisms of neuronal communication by taking into account how the assumed mechanisms (i.e., temporal synchronization patterns) may change across different life periods. However, the comparison of individuals from different life-periods is challenging, particularly for electrophysiological or fMRI studies. A range of possible confounds may affect task performance or the imaging measures themselves (D'Esposito et al., 2003; Gazzaley and D’Esposito, 2005; Rugg and Morcom, 2005). In the present study, we opted for a task that (a) is relatively easy to perform for all age groups, and (b) allows for the parametric variation of input (i.e., size) in order to observe neuronal processes of interest (i.e., temporal synchronization in early visual processing) without the confounding factor of lifespan differences in task proficiency. By using a simple choice-reaction task, we sought to minimize the contamination of observed age differences in neuronal mechanisms of visual coding with concomitant age differences in cognitive proficiency such as attention, working memory, and executive functions (Li et al., 2004; Rugg and Morcom, 2005).

After a phase of synaptic overproduction and pruning (e.g., Huttenlocher and de Courten, 1987), occipital areas show relatively little senescence-related changes compared to, for example, prefrontal regions (Sowell et al., 2003; Raz et al., 2005), and provide the main input for higher order cognitive processes requiring visual information (Tobimatsu and Celesia, 2006). Therefore, we chose gamma-band synchronization in early visual perception as a target mechanism. Accordingly, we adopted a task designed by Busch and colleagues (Busch et al., 2004) that allows investigating the influence of variations in visual input on synchronization of retinotopically organized cell assemblies in early visual processing areas. The paradigm is based on the observation that stimuli with greater visual angle engage larger cell assemblies in early visual regions (e.g., V1, V2 and V3). If maturational, learning- or senescence-related changes in neuroanatomy and neurochemistry indeed affect mechanisms of neuronal coding, age-differential patterns in gamma-band measures of power and phase-stability ought to be found.

Following the temporal synchronization hypothesis, the larger the stimulus, the larger the neuronal assembly that has to be bound to code for the respective stimulus. Traditionally, timevarying spectral power measures of gamma oscillations are used to quantify the synchronization of local cell assemblies. However, spectral power conflates the influence of changes in the amplitude of oscillations with changes in phase-synchronization. While differences in power measures may therefore reflect both the size of the neuronal assembly engaged in stimulus processing as well as the degree of temporal synchronization, measures of phase-stability just represent the temporal relationship of oscillations of a given frequency (cf., Lachaux et al., 1999; Rosenblum et al., 2001; Tass et al., 1998). Besides measuring spectral power changes, we therefore also investigated effects of increasing stimulus size on the inter-trial phase-stability of ongoing oscillations as quantified with the phase-locking index (PLI, cf. Gruber et al., 2005).

\section{Materials and methods}

\subsection{Participants}

The effective sample comprised 17 children (mean age: 11.7 years, range: $10.6-12.3$ years, 8 female), 16 younger adults (mean age: 23.4 years, range: 20.0-26.3 years, 8 female), and 17 older adults (mean age: 72.5 years, range: $70.3-75.8$ years, 9 female). The participants were recruited from the participant pool of the Max Planck Institute for Human Development, Berlin, Germany (MPIB). All participants provided written informed consent according to institutional guidelines of the ethics committee of the MPIB. All participants were right-handed, as assessed with the Edinburgh Handedness Inventory (Oldfield, 1971), reported to be in good health with no known history of neurological or psychiatric diseases, and were paid 27 Euro (about \$ 34 US) for participation. In addition to participants included in the effective sample, data from two children, four younger adults, and four older adults were also recorded. However, these data had to be discarded from further analyses after artifact rejection due to excessive muscle noise or technically unsatisfactory recordings resulting in less than 50 artifact-free trials. 


\subsection{Procedure}

Prior to electrode placement, participants filled out a demographic and health related questionnaire. Visual acuity and two marker tests of fluid and crystallized intelligence were assessed as well.

Visual acuity was measured in Snellen decimal units at two different distances using a standard table with Landolt rings (Geigy, 1977). Close visual acuity was measured separately for the left and the right eye at a distance of $25 \mathrm{~cm}$. Distance visual acuity was assessed binocularly at a distance of $7.5 \mathrm{~m}$ to the participant. All measures were taken with the best optical correction (i.e., glasses) available to the participant because the experimental procedures were carried out in the same mode.

Two cognitive tests were used to document the age typicality of the sample. Perceptual speed as a broad fluid marker was assessed with the Digit Symbol Substitution Test (Wechsler, 1958), and verbal knowledge as a broad crystallized marker was assessed with the Spot-a-Word test (see Lindenberger et al., 1993, adapted from Lehrl, 1977).

After electrode placement, participants were seated comfortably in a dimly lit as well as electromagnetically and acoustically shielded room. The EEG measurement started with a 6-min relaxation phase (resting-state EEG: 3 min with eyes closed and $3 \mathrm{~min}$ with eyes open). Afterwards, the subjects performed two practice blocks ( 12 trials per block) and four experimental blocks (120 trials per block) of the visual choice-reaction task described below. The whole session lasted approximately $2.5 \mathrm{~h}$.

\subsection{Stimuli and task}

Stimulus presentation and recording of behavioral responses was controlled with the E-Prime v1.2 software (Psychology Software Tools, Inc., Pittsburgh, PA, USA). Stimuli consisted of black squares and circles presented on a white background via a Liquid Crystal Monitor (LCD, refresh rate: $60 \mathrm{~Hz}$ ). The participants were instructed to press an assigned button of the response box with the index finger of one hand if the stimulus was a square, and to press another button with the index finger of the opposite hand if it was a circle. Assignment of response hand to squares or circles was counterbalanced across participants. The size of the stimuli was varied in three levels, subtending $2^{\circ}$ (small), $4^{\circ}$ (medium), and $8^{\circ}$ (large) of visual angle from the participants' viewing distance of exactly $105 \mathrm{~cm}$. Within each experimental block, both types of stimuli in each size level appeared with equal probability in a pseudo-randomized order that was fixed across all participants.

Each trial started with a black fixation cross presented in the center of the screen for $300 \mathrm{~ms}$. The fixation cross was followed by a variable blank screen with varying pre-stimulus intervals (mean duration of $700 \mathrm{~ms}$, varied in discrete intervals ranging from $600 \mathrm{~ms}$ to $800 \mathrm{~ms}$ in $50 \mathrm{~ms}$ steps with equal probability). Afterwards, the stimuli were presented for $300 \mathrm{~ms}$. Following stimulus presentation a post-stimulus blank screen interval was shown for $500 \mathrm{~ms}$. In order to keep a long time interval surrounding the stimulus presentation free from motor-related activity, subjects were instructed to withhold their response until the screen prompted for their response. Note that this manipulation compromised the interpretability of reaction time data in this study. The response screen appeared after the post-stimulus blank screen interval and remained for $2000 \mathrm{~ms}$ or until the subject responded. Two consecutive trials were separated by an inter-trial interval of $500 \mathrm{~ms}$. On average, one trial lasted for about $4 \mathrm{~s}$. Each participant performed four blocks of 120 trials each, yielding a total of 480 trials (i.e., 80 trials of squares and 80 trials of circles for each of the three stimulus sizes). Each test block was followed by a short break before the start of the next block. In total, the experimental task took $45 \mathrm{~min}$.

\subsection{EEG acquisition and preprocessing}

EEG was recorded continuously (BrainAmp amplifiers, Brain Products $\mathrm{GmbH}$, Gilching, Germany) from $60 \mathrm{Ag} / \mathrm{Ag}-\mathrm{Cl}$ electrodes embedded in an elastic cap (EASYCAP GmbH, Herrsching, Germany). To monitor eye movements, three additional electrodes were placed at the outer canthi (horizontal EOG), and below the left eye (vertical EOG). During recording, all electrodes were referenced to the right mastoid electrode, the left mastoid electrode was recorded as an additional channel, and ground was placed at location AFz. Electrode impedances were maintained below $5 k \Omega$ before recordings. The EEG was recorded with a pass-band of $0.1-250 \mathrm{~Hz}$ and digitized with a sampling rate of $1000 \mathrm{~Hz}$ for later off-line analyses.

Preprocessing was performed in three steps. First, the EEG was re-referenced to mathematically linked mastoids. Second, 3-s data epochs were extracted from $-1.5 \mathrm{~s}$ to $1.5 \mathrm{~s}$ (with respect to stimulus onset). Third, the extracted segments were semi-automatically scanned for eye blinks, eye movements, and excessive muscle activity in the time interval from $0.5 \mathrm{~s}$ prior to $0.8 \mathrm{~s}$ post-stimulus. For each of these artifacts, an appropriate metric with specific sensitivity for the respective artifact was computed, and a rejection threshold was empirically determined for each subject (Bauer et al., 2006; Delorme et al., 2007). Afterwards, the remaining epochs were visually inspected and artifacts not detected automatically were removed.

\subsection{Data analysis}

Time- and frequency-domain analyses of the EEG data were carried out using the FieldTrip software package (developed at the F.C. Donders Centre for Cognitive Neuroimaging, Nijmegen, The Netherlands; http://www2.ru.nl/fcdonders/fieldtrip/) and custommade routines operated in MATLAB 7.1 (The MathWorks Inc., Natick, MA, USA).

In light of previous results showing no effect for geometrical shape (i.e., circle versus square; see Busch et al., 2004), we collapsed data based on circle and square stimuli at each size for further analysis.

\subsubsection{Event-related potentials (ERP)}

ERPs reflect changes of ongoing EEG activity evoked by the stimulus that show some invariance across trials. As visual stimulus properties (e.g., size, luminance or spatial frequency) are known to affect the amplitude and latency of early ERP components (Celesia, 1993), we additionally assessed P1 and N1 amplitude and latency. For the analysis of ERP components, all artifactfree EEG epochs were $20 \mathrm{~Hz}$ low-pass filtered and averaged, separately for each participant and stimulus size, in a time range from $-0.5 \mathrm{~s}$ to $0.8 \mathrm{~s}$ surrounding stimulus onset. Prior to averaging, each single trial was baseline-corrected by subtracting the mean amplitude in a time-window from $-0.1 \mathrm{~s}$ to $0 \mathrm{~s}$ with respect to stimulus onset.

For statistical analyses of ERP responses, peak amplitudes and the corresponding latencies were extracted from participant- and size-specific ERPs. The P1 (N1) component was defined as the most positive (negative) going deflection in a time interval ranging from $80 \mathrm{~ms}$ to $180 \mathrm{~ms}$ ( $150 \mathrm{~ms}$ to $250 \mathrm{~ms}$ ) post-stimulus. Given the current studies' focus on early visual processing, we determined P1 and $\mathrm{N} 1$ peaks and latencies for electrode locations covering occipital areas (electrode region of interest: $01, \mathrm{Oz}, \mathrm{O} 2$ ). 


\subsubsection{Time-frequency decomposition}

To derive time-varying power and phase we applied a Morletwavelet-based time-frequency (TF) decomposition of the EEG data (Tallon-Baudry et al., 1997, 1998). In the present study, the signal of interest $(s(t))$ was convoluted by complex Morlet-wavelets $w\left(t, f_{0}\right)$ having a Gaussian shape in both time and frequency domains (Kronland-Martinet et al., 1987) around its central frequency $\left(f_{0}\right)$ :

$w\left(t, f_{0}\right)=A * \exp \left(-t^{2} / 2 \sigma_{t}^{2}\right) * \exp \left(2 i \pi f_{0} t\right)$

The standard deviation in the frequency-domain $\left(\sigma_{f}\right)$ is related to the standard deviation in the time-domain $\left(\sigma_{t}\right)$ with $\sigma_{f}=1 / 2 \pi \sigma_{t}$. Wavelets were normalized so that their total energy is 1 , with the normalization factor $A$ set to $\left(\sigma_{t} \sqrt{\pi}\right)^{-1 / 2}$. A family of wavelets used for TF decomposition is characterized by a constant ratio $c=f_{0} / \sigma_{f}$. The wavelet-family chosen in the current study was defined by $c=7$ (Farge, 1992; Grossmann et al., 1989) with $f_{0}$ ranging from 25 to $150 \mathrm{~Hz}$ in steps of $1 \mathrm{~Hz}$. This results in decreasing wavelet duration $\left(2 \sigma_{t}\right)$ and increasing spectral bandwidth $\left(2 \sigma_{f}\right)$ with increasing center frequency $f_{0}$, (i.e., the time resolution increases while the frequency resolution decreases).

The convolution of the signal by a family of Morlet-wavelets results in complex-valued wavelet-coefficients $\left(W T_{t, f_{0}}\right)$ for each $\mathrm{TF}$ bin in the TF plane:

$W T_{t, f_{0}}=s(t) \otimes w\left(t, f_{0}\right) ; \quad W T_{t, f_{0}}=$ complex

The time-varying power $\left(P_{t, f_{0}}\right)$ of the signal for a given center frequency is given by the squared norm of the respective waveletcoefficients:

$P_{t, f_{0}}=\left|W T_{t, f_{0}}\right|^{2}$

The time-varying phase $\left(\Phi_{t, f_{0}}\right)$ for each center frequency is given by the real and imaginary parts of the complex wavelet coefficients as:

$\Phi_{t, f_{0}}=\arctan \left(\frac{\operatorname{imag}\left(W T_{t, f_{0}}\right)}{\operatorname{real}\left(W T_{t, f_{0}}\right)}\right)$

\subsubsection{Evoked power}

To reveal the evoked fraction of the gamma-band response, we applied the TF decomposition as described above to the unfiltered ERP. For this purpose, the whole unfiltered 3-s segments for each electrode, participant, and stimulus size were averaged separately. Afterwards, the unfiltered ERP was wavelet-transformed to derive time-varying power estimates in the gamma-frequency band.

To quantify the increase in evoked power related to stimulus processing and to account for possible age differences in noise levels, we calculated the relative increase in post-stimulus evoked power $(r e l E P)$ in relation to a pre-stimulus reference period:

$\operatorname{relEP} P_{t_{P S} . f_{0}}=\frac{E P\left(t_{P S}, f_{0}\right)-M_{E P B a s e l i n e}\left(f_{0}\right)}{M_{E P B a s e l i n e}\left(f_{0}\right)} ; \quad t_{P S} \in[0 \mathrm{~s}, 0.8 \mathrm{~s}]$

Here, $\left(M_{\text {EPBaseline }}\left(f_{0}\right)\right)$ reflects the mean evoked power for each center frequency in a time range from $-0.3 \mathrm{~s}$ to $-0.05 \mathrm{~s}$ in relation to stimulus onset, while $\left(E P\left(t_{P S}, f_{0}\right)\right)$ represents the evoked power estimates at each post-stimulus $(0-0.8 \mathrm{~s}) \mathrm{TF}$ point.

The exact frequency in the gamma range showing the maximal response to experimental variations varied considerably across participants. Therefore, the frequency for statistical analyses was determined individually for each participant and size level (cf. Busch et al., 2004, 2006; Gruber and Müller, 2005; for similar approaches). For this purpose, the individual gamma-frequency (IGF) was determined based on the average relEP from a parietooccipital region-of-interest (ROI), comprising the electrodes: P1, $\mathrm{Pz}, \mathrm{P} 2, \mathrm{PO} 3, \mathrm{POz}, \mathrm{PO} 4, \mathrm{O} 1, \mathrm{Oz}, \mathrm{O} 2$. The IGF was defined as the fre- quency showing the maximum relative increase in evoked power in the time range from $0.05 \mathrm{~s}$ to $0.2 \mathrm{~s}$ between 30 and $148 \mathrm{~Hz}$. Afterwards, we extracted the amplitude time-course for each subject and condition at the IGF, and averaged the traces to form electrode regions of interest (see below).

\subsubsection{Phase-locking index}

To quantify the phase relation of ongoing oscillations to stimulus processing, we estimated the PLI from the complex TF representations based on wavelet decompositions of single trials (cf. Lachaux et al., 1999; Rosenblum et al., 2001; Tass et al., 1998). The PLI, as used in this report, measures the stability of phases across trials.

The PLI was calculated as follows. The EEG signal from each single trial ( $N$ artifact-free, non-baseline corrected raw epochs for each participant and stimulus size condition; $-1.5 \mathrm{~s}$ to $1.5 \mathrm{~s}$ ) was subjected to wavelet-based time-frequency decomposition as described above. The resulting complex valued wavelet-coefficients $\left(W T_{t, f_{0}}\right)$ for each TF bin in the TF plane from $-500 \mathrm{~ms}$ to $800 \mathrm{~ms}$ (zero-padding for the remaining part of the epoch) were normalized by their vector length and averaged across trials. The PLI for each time-point and center frequency was then derived by taking the norm of the resultant mean direction vector (Fisher, 1993; Mardia, 1972):

$P L I_{t, f_{0}}=\left|1 / N \sum_{n} \frac{W T_{t f_{0}}(n)}{\left|W T_{t, f_{0}}(n)\right|}\right|$

PLI values range between 0 and 1 , with 1 indicating perfect phase-stability and 0 indicating a random (uniform) distribution of phases across trials (Rosenblum et al., 2001).

In order to determine meaningful increases in phase locking due to stimulus processing, we converted the post-stimulus PLIvalues into $T$-scores. This was achieved by estimating the mean $P L I$ at each TF bin and corresponding standard deviation through jackknife (Efron and Tibshirani, 1993). In each jackknife-cycle, one of the $N$ available TF representations for each subject and condition was systematically left out, while the PLI for each TF bin was computed from the remaining $N-1$ maps. This results in $N$ TF representations of the PLI. T-Scores were then calculated according to the formula:

$T_{t_{P S} f_{0}}^{P L}=\frac{M_{P L I}\left(t_{P S}, f_{0}\right)-M_{P L I B a s e l i n e}\left(f_{0}\right)}{\sqrt{\frac{\sigma_{P L B B a s e l i n e}^{2}+\sigma_{P L I}^{2}\left(t_{P S} f_{0}\right)}{N}}} ; \quad t_{P S} \in[0 \mathrm{~s}, 0.8 \mathrm{~s}]$

In this equation, $M_{\text {PLIBaseline }}\left(f_{0}\right)$ and $\sigma_{\text {PLIBaseline }}$ represent the mean PLI along with the corresponding standard deviation for each center frequency in a reference interval $(-0.3 \mathrm{~s}$ to $-0.05 \mathrm{~s})$ prior to stimulus onset. The quantities $M_{P L I}\left(t_{P S}, f_{0}\right)$ and $\sigma_{P L I}\left(t_{P S}, f_{0}\right)$ reflect the mean PLI and the corresponding standard deviation for each post-stimulus TF bin ( $0-0.8 \mathrm{~s})$ as estimated via the jackknife procedure. These $T$-scores were the basis for further statistical analyses.

For statistical analyses, we extracted the $T$-score time-course for each participant's IGF as determined from the evoked power analyses and averaged the traces to form regions of interest (see below). The maximum $T$-score for $P L I$ was then determined in a time range from $0.05 \mathrm{~s}$ to $0.2 \mathrm{~s}$ post-stimulus.

\subsubsection{Statistical analysis}

In order to reduce data complexity, and based on the assumption that evoked gamma-band responses during processing of simple geometric shapes should be most pronounced over early visual areas (Busch et al., 2004), we collapsed ERP traces (O1, Oz, O2) as well as TF representations (P1, Pz, P2, PO3, POz, PO4, O1, Oz, O2) across electrodes to form (parieto-)occipital ROIs. Selection of ROIs was guided by visual inspection of the maxima for the measures of 
interest. P1 and N1 peak amplitudes and latencies as well as the peak of the evoked power change and the maximum PLI T-value were determined for the respective ROI.

For each dependent measure of interest, extreme outliers were removed if the respective value exceeded a threshold of $\pm 2 *$ interquartile range (Tukey, 1977), resulting in corresponding differences in the degrees of freedom among the statistical tests reported below. Afterwards, analyses were conducted with the Proc Mixed procedure in SAS (SAS 9.1 for Windows). This procedure implements multi-level random-coefficient modeling, also termed mixed-model methodology for repeated measures. Because of maximum-likelihood estimation, and unlike analysis of variance, mixed-model methodology does not treat data as missing in a list-wise fashion but considers all available data points. In addition, mixed-model methodology also permits the relaxation of two main constraints. Specifically, it (a) allows for heterogeneous variance and covariance structures across age groups and (b) flexibly estimates covariance structures in order to provide valid standard errors and statistical tests for repeated measures data instead of assuming compound symmetry structure (Littell et al., 2002). Allowing for differences in variance and covariance between age groups and size conditions was not of major interest in the present investigation, but mainly served the purpose of arriving at accurate estimations fixed effects (i.e., group differences in means). Given that the experimental manipulation in the study most likely led to differences in the covariance and variance of EEG measures within and across age groups and size conditions, we decided to fit an unstructured covariance matrix to the data. The unstructured covariance matrix is the most general unconstrained structure, with unique variances and covariances estimated for each age group and size condition.

Each set of analyses started with an omnibus mixed model to assess the effects of the factors SIZE (three levels: $2^{\circ}, 4^{\circ}, 8^{\circ}$ of visual angle) and AGEGROUP (three levels: children, younger adults, older adults). If necessary, the omnibus mixed models were followed up by appropriate contrasts. The alpha level for all statistical analyses was set to $\alpha=.05$, with Bonferroni adjustments when needed. For reliable effects and for trends $(.1>p>.01)$, effect sizes are indicated by reporting partial eta-squared $\left(\eta_{\mathrm{p}}^{2}\right.$; Hullett and Levine, 2003).

\section{Results}

\subsection{Behavioral and covariate measures}

Overall, participants in all age groups performed the visual discrimination task equally well, attaining a grand mean of $99.3 \%$ correct responses (minimum: 91.3\%; maximum: 100\%) across all age groups and size levels. As confirmed by a univariate mixed measures ANOVA, neither AGEGROUP nor SIZE produced any significant main or interaction effects, all $F<1.4$, all $p s>0.2$.

To evaluate the psychometric and visual acuity covariate measures, we applied univariate ANOVAs with AGEGROUP as between-subjects factor, followed by appropriate pairwise contrasts of the three age groups. Table 1 summarizes the behavioral covariates for each age group.

Table 1

Means and standard errors (in parentheses) for visual acuity (close and far vision), digit symbol substitution, and Spot-a-Word performance in each age group.

\begin{tabular}{lrcr}
\hline & \multicolumn{1}{c}{ Children } & Younger adults & Older adults \\
\hline Close vision & $0.97(0.02)$ & $0.93(0.03)$ & $0.52(0.05)$ \\
Far vision & $1.26(0.11)$ & $1.19(0.11)$ & $0.67(0.07)$ \\
Digit symbol & $46.94(1.85)$ & $66.31(3.00)$ & $46.94(2.41)$ \\
Spot-a-Word & $10.39(0.66)$ & $23.28(1.07)$ & $26.19(0.99)$ \\
\hline
\end{tabular}

With respect to the performance in the psychometric marker tasks for cognitive pragmatics (Spot-a-Word, SAW) and mechanics (Digit Symbol Substitution, DSS), expected lifespan patterns were observed, namely: (1) a continuous increase in verbal knowledge across the lifespan (children < younger adults < older adults; $\left.F(2,49)=81.7, p<.05, \eta^{2}=.78\right)$, and ( 2 ) an inverted U-shaped lifespan function for the DSS scores (children $=$ older adults $<$ younger adults; $F(2,49)=20.5, p<.05, \eta^{2}=.47$ ). Concerning visual acuity, older adults revealed lower scores for close, $F(2,49)=59.7$, $p<.05, \eta^{2}=.71$, as well as far vision, $F(2,49)=11.6, p<.05$, $\eta^{2}=.33$, whereas younger adults and children did not differ in both measures, all $F<1$, all $p s>0.4$.

\subsection{Event-related potentials}

As can be inferred from visual inspection of Fig. 1, children produced overall larger ERP amplitudes than the adult age groups. Furthermore, when directly examining an occipital electrode ROI $(\mathrm{O} 1, \mathrm{Oz}, \mathrm{O} 2)$ overlying early visual areas, we also recognized modulation of the $\mathrm{P} 1$ and $\mathrm{N} 1$ components by stimulus size.

Accordingly, the omnibus tests of the P1 and N1 amplitudes revealed main effects of factor AGEGROUP, P1: $F(2,47)=19.33$, $p<.05, \eta_{\mathrm{p}}^{2}=.45 ; \mathrm{N} 1: F(2,44)=14.89, p<.05, \eta_{\mathrm{p}}^{2}=.40$, reflecting higher peak amplitudes for children compared to younger and older adults, P1: $F(1,47)=38.44, p<.05, \eta_{\mathrm{p}}^{2}=.45 ; \mathrm{N} 1: F(1,45)=29.37$, $p<.05, \eta_{\mathrm{p}}^{2}=.39$, whereas the latter two did not differ, P1: $F(1,47)=0.11, p=.74 ; \mathrm{N} 1: F(1,44)=0.50, p=.48)$. Furthermore, also the variation of stimulus size affected the P1/N1 amplitudes reflected in main effects of factor SIZE, P1: $F(2,46)=10.75$, $p<.05, \eta_{\mathrm{p}}^{2}=.32 ; \mathrm{N} 1: F(2,41)=15.43, p<.05, \eta_{\mathrm{p}}^{2}=.43$, with higher peak amplitudes for larger stimuli.

With respect to the P1 and N1 latencies, a similar pattern of results emerged. The omnibus tests revealed main effects of AGEGROUP, P1: $F(2,47)=4.52, p<.05, \eta_{\mathrm{p}}^{2}=.16 ; \mathrm{N} 1: F(1,46)=21.82$, $p<.05, \eta_{\mathrm{p}}^{2}=.48$, reflecting slower peak latencies for children compared to younger and older adults, P1: $F(1,47)=7.51, p<.05$, $\eta_{\mathrm{p}}^{2}=.14 ; \mathrm{N} 1: F(1,46)=37.10, p<.05, \eta_{\mathrm{p}}^{2}=.44$. While there was no differences between both adult groups concerning P1 latencies, $F(1,47)=1.41, p=.24$, older adults exhibited shorter N1 latencies compare to the younger ones, $F(1,47)=6.24, p<.05, \eta_{\mathrm{p}}^{2}=.12$. In addition, also main effects for factor SIZE, P1: $F(2,47)=20.45$, $p<.05, \eta_{\mathrm{p}}^{2}=.47 ; \mathrm{N} 1: F(2,43)=28.59, p<.05, \eta_{\mathrm{p}}^{2}=.57$, were obtained, indicating shorter peak latencies for larger stimuli. Neither for the P1 and N1 amplitudes, nor for the respective latencies, reliable SIZE $\times$ AGEGROUP interactions were observed, all $F<1.46$, all $p>.23$.

\subsection{Individual gamma frequencies}

Fig. 2 depicts the IGF distribution for each age group and size level. The omnibus mixed model resulted in a main effect of factor AGEGROUP, $F(2,48)=9.14, p<.05, \eta_{\mathrm{p}}^{2}=.27$. Post-hoc contrasts revealed higher IGF for children compared to both adult groups, $F(1,47)=14.42, p<.016, \eta_{\mathrm{p}}^{2}=.23$, as well as a trend for higher IGF for younger compared to older adults, $F(1,49)=3.97, p=.052$, $\eta_{\mathrm{p}}^{2}=.07$ (see also Table 2). Neither the main effect of SIZE, nor the interaction between SIZE and AGEGROUP reached significance, both $F<0.78$, both $p>.54$. Table 2 displays the mean IGF for each age group and size level.

\subsection{Lifespan differences in visually evoked gamma power}

The increasing size of visual stimuli led to marked increases in evoked gamma power around $100 \mathrm{~ms}$ after stimulus onset in children, younger adults, and older adults (Fig. 3). However, the relative amount of gamma power evoked by processing the visual 

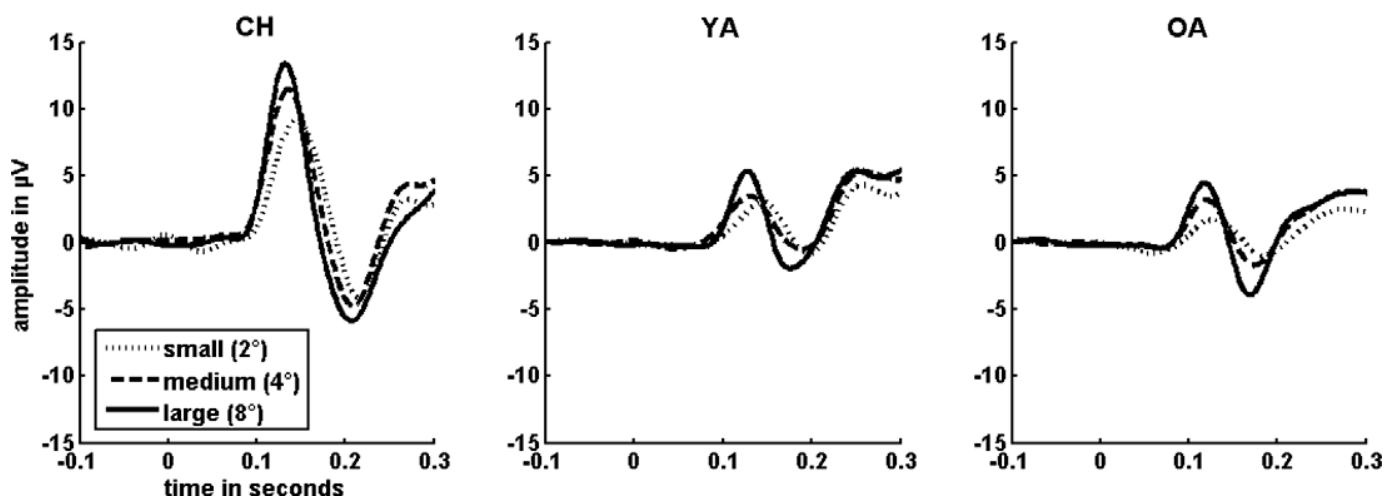

Fig. 1. Grand-average event-related potentials (ERP) separately for children ( $\mathrm{CH}$, left-hand side), younger adults (YA, middle) and older adults (OA, right-hand side) at each size level ( $2^{\circ}$ : dotted line; $4^{\circ}$ : dashed line; $8^{\circ}$ : solid line), averaged across occipital electrodes $(01, \mathrm{Oz}, \mathrm{O2})$.

input seemed to be different across age groups. The left-hand side of Fig. 4 depicts the mean of the peak relative change in evoked power (relEP) for each age group and size level.

The mixed model omnibus test with factors SIZE and AGEGROUP revealed a main effect of factor SIZE, $F(2,44)=26.87$, $p<.05, \eta_{\mathrm{p}}^{2}=.55$, reflecting a stronger increase in evoked gamma power with increasing size. There also was a main effect of factor AGEGROUP, $F(2,42)=3.53, p<.05, \eta_{\mathrm{p}}^{2}=.14$. Post-hoc pairwise comparisons showed that overall children exhibited less relEP compared to younger adults, $F(1,43)=7.04, p<.016, \eta_{\mathrm{p}}^{2}=.14$. However, neither the contrast of older adults with children, $F(1,42)=1.28, p>.26$, nor with younger adults, $F(1,43)=2.42$, $p>.12$, reached significance. Furthermore, we observed a significant SIZE $\times$ AGEGROUP interaction, $F(4,44)=3.12, \quad p<.05$, $\eta_{\mathrm{p}}^{2}=.22$, suggesting that the relative increase in evoked gamma power differed across age groups. Comparing the three age groups at each size level, revealed that the age groups did not differ for stimuli of size $4^{\circ}, \mathrm{Fs}<0.76, \mathrm{ps}>.38$. However, for $2^{\circ}$ stimuli, children showed lower relEP compared to younger, $F(1,47)=10.68$; $p<.012, \eta^{2}=.18$, and older adults, $F(1,47)=4.82, p=.03, \eta^{2}=.08$, while both adult groups did not differ from each other, $F(1,47)=1.22 ; p=.27$. By contrast, for stimuli of $8^{\circ}$, young adults exhibited significantly higher relative evoked power compared to children, $F(1,42)=5.89 ; p<.016, \eta^{2}=.12$, and a trend for higher values compared to older adults, $F(1,42)=3.66 ; p<.065, \eta^{2}=.08$, while children and older adults did not differ $F(1,42)=0.28$,

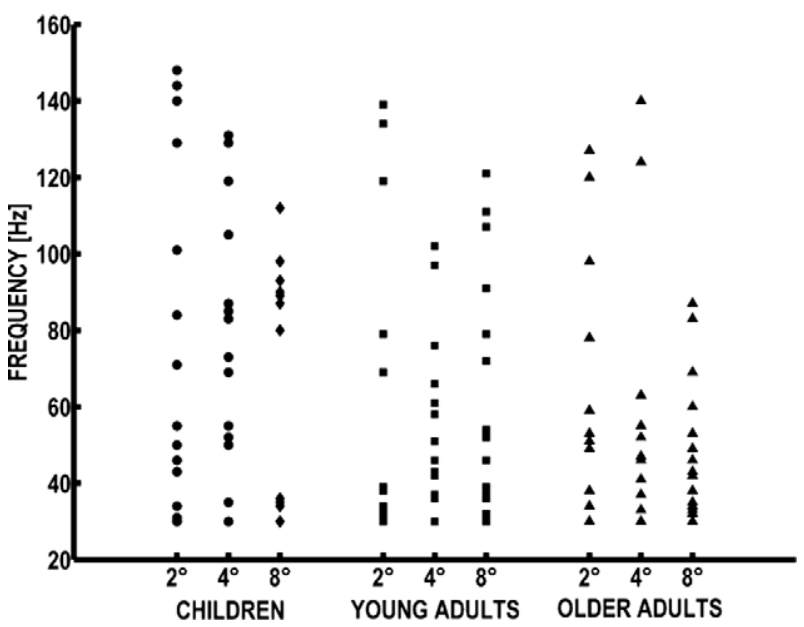

Fig. 2. Distribution of individual gamma frequencies at each size level $\left(2^{\circ}, 4^{\circ}\right.$, or $\left.8^{\circ}\right)$, separately for the three age groups (children, young adults, older adults). At each size level individual subjects are depicted by circles (children), squares (young adults), or triangles (older adults). $p=.59$. Interaction contrasts confirmed that the gain in relative evoked power with increasing size was more pronounced for younger adults compared to children and older adults, $F(1,42)=7.27$, $p<.016, \eta_{\mathrm{p}}^{2}=.15$, whereas the later two groups did not differ, $F(1,43)=0.03, p=.87$.

With respect to the latency of the peak relEP, no reliable effects of AGEGROUP, SIZE, or their interaction were found, $F s<1.49$, ps $>.23$.

\subsection{Lifespan differences in gamma phase-locking across trials}

Increasing stimulus size led to increased temporal stability of processing in the gamma-frequency range for all three age groups (Fig. 5). However the increase in phase-stability across trials while processing stimuli of increasing size was different across age groups as evidenced in the peak of the post-stimulus $T$-scores for PLI (right -hand side of Fig. 4).

The omnibus test revealed a main effect of SIZE, $F(2,45)=34.97$, $p<.05, \eta_{\mathrm{p}}^{2}=.61$, as well as a main effect of AGEGROUP, $F(2,45)=3.60, p<.05, \eta_{\mathrm{p}}^{2}=.14$. Across all size levels, younger adults showed higher PLI $T$-scores than children, $F(1,45)=7.10$; $p<.016, \eta^{2}=.14$, but they did not differ from older adults, $F(1,45)=2.66, p=.11$. The difference between older adults and children was not significant, $F(1,45)=1.03, p=.32$ Additionally, we observed a significant SIZE $\times$ AGEGROUP interaction, $F(4,45)=7.27, p<.05, \eta_{\mathrm{p}}^{2}=.39$. Pairwise contrasts of the three age groups at each size level revealed that older adults showed highest PLI $T$-values for stimuli of size $2^{\circ}$ compared to children, $F(1,47)=22.58, \quad p<.016, \quad \eta_{\mathrm{p}}^{2}=.32$, and younger adults, $F(1,47)=7.69, p<.016, \eta_{\mathrm{p}}^{2}=.14$, while the latter did not differ from each other, $F(1,47)=3.64, p=.06$. However, for $8^{\circ}$ stimuli, younger adults differed significantly from children, $F(1,46)=5.87 ; p<.016$, $\eta_{\mathrm{p}}^{2}=.11$, and marginally from older adults, $F(1,46)=4.75, p=.03$, $\eta_{\mathrm{p}}^{2}=.09$, while the children and older adults did not differ from each other, $F(1,46)=0.04 ; p=.83$. For stimuli of size $4^{\circ}$, no reliable differences between age groups were observed, $F s<4.21, p s>.046$.

Concerning the latency of the peak PLI T-values, no significant effects of AGEGROUP, SIZE, or their interaction were found, $F s<2.98, p s>.06$.

Table 2

Mean individual gamma-frequency (standard errors in parentheses) separately for each age group and size-level.

\begin{tabular}{llll}
\hline & Children & Younger adults & Older adults \\
\hline SIZE $2^{\circ}$ & $79.7(10.9)$ & $56.1(9.9)$ & $54.2(7.9)$ \\
SIZE $4^{\circ}$ & $73.4(8.3)$ & $52.6(5.7)$ & $52.2(7.7)$ \\
${\text { SIZE } 8^{\circ}}^{60.2(7.7)}$ & $60.9(7.9)$ & $46.7(4.4)$ \\
\hline
\end{tabular}


A

CHILDREN

SIZE $2^{\circ}$

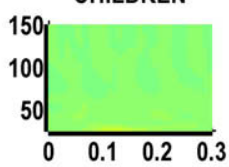

SIZE $4^{\circ}$

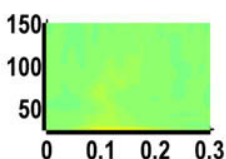

SIZE $8^{\circ}$

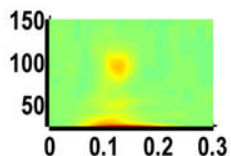

B

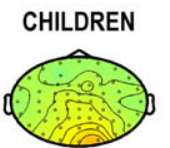

YOUNG ADULTS
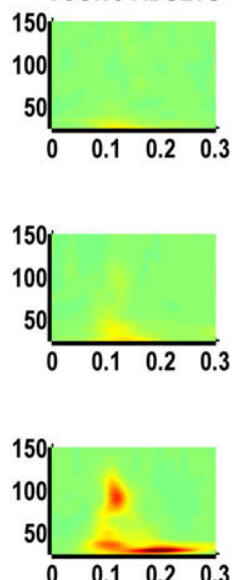

YOUNG ADULTS
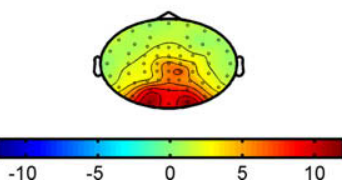

OLDER ADULTS
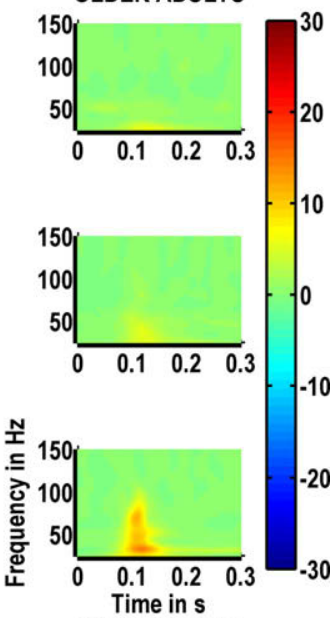

OLDER ADULTS

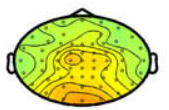

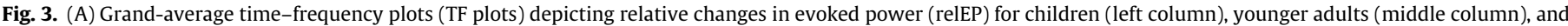

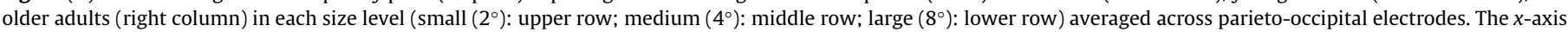

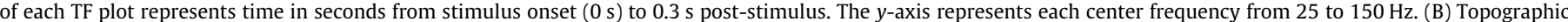

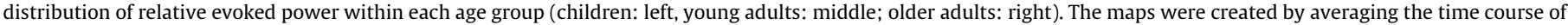
relEP at each subject's individual gamma-frequency across size conditions separately for each age group in the time range from $50 \mathrm{~ms}$ to $200 \mathrm{~ms}$ post-stimulus.

\section{Discussion}

This study investigated lifespan differences in ERP and oscillatory correlates of early visual processing in three age groups, covering the age ranges from middle childhood to early old age. We assume that the task-related electrophysiological activity observed in younger adults reflects a fully mature neuronal system that is not yet altered by major senescent changes or plastic adaptations to such changes. Hence, we take younger adults' electrophysiological activity as a point of reference for characterizing the activity of children and older adults.

In comparison to younger adults, children's P1 and N1 ERP components showed higher amplitudes and increased latencies. At the same time, children exhibited reduced evoked gamma power and a less pronounced coupling between the degree of inter-trial phase-stability and stimulus size. In contrast, older adults differed
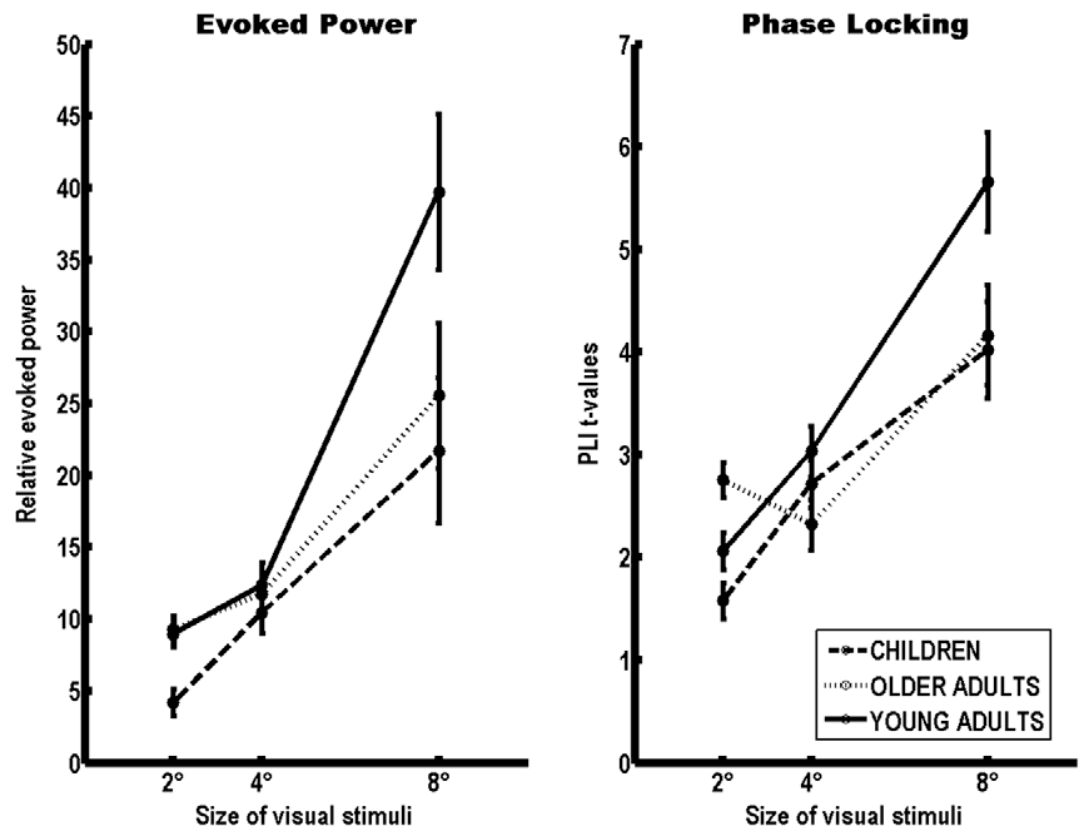

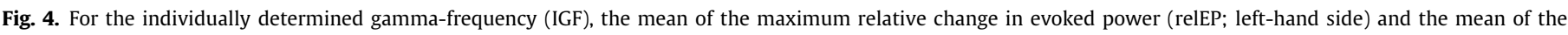

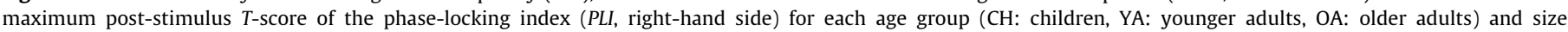

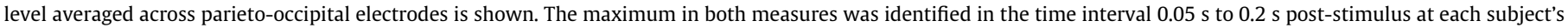
IGF. 
A
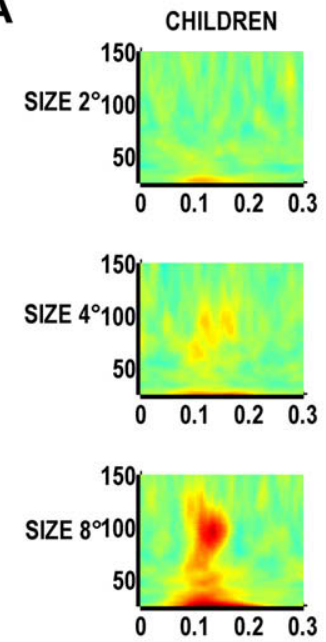

YOUNG ADULTS
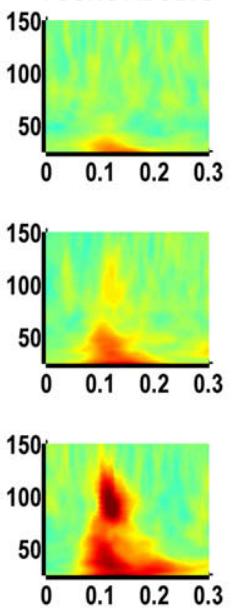

OLDER ADULTS

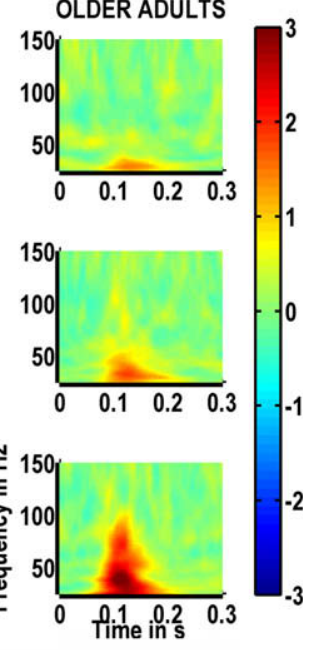

OLDER ADULTS

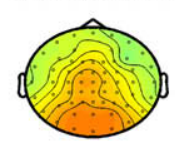

B

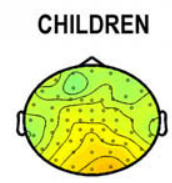

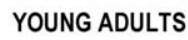

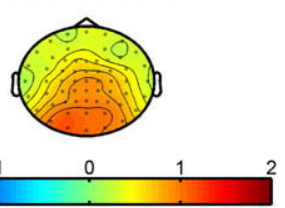

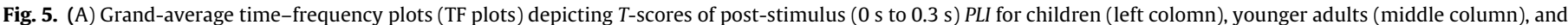

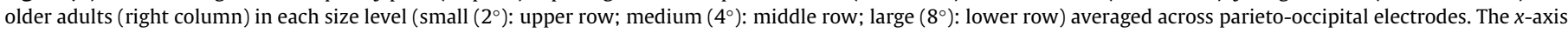

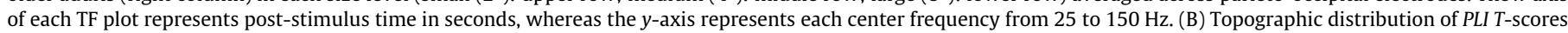

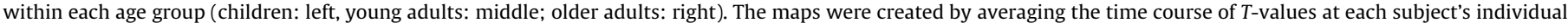
gamma-frequency across size conditions separately for each age group in the time range from 50 ms to 200 ms post-stimulus.

less and in different ways from younger adults than children. In comparison to younger adults, they show reduced evoked gamma power but similar levels of phase-stability in the gamma-frequency band.

As intended, the uniformly high levels of task proficiency in all age groups greatly reduced the possible contribution of age group differences in performance levels to age group differences in observed electrophysiological activity (Rugg and Morcom, 2005). In addition, the rather complex pattern of age differences in electrophysiological activity is difficult to explain by the pattern of similarities $(\mathrm{CH}=\mathrm{YA})$ and differences $(\mathrm{OA}<\mathrm{YA}, \mathrm{CH})$ in visual acuity.

\subsection{Effects of increasing stimulus size on evoked gamma power and inter-trial phase-stability}

The observed increase in evoked gamma power with increasing stimulus size replicates earlier findings by Busch and colleagues in young adults (Busch et al., 2004). Recent EEG and MEG studies located the sources for early gamma-band responses in occipital areas (Gruber et al., 2006, 2008), especially in the posterior ends of the calcarine sulci of the two hemispheres (Hoogenboom et al., 2006). These locations are consistent with sources in the foveal confluence of the early visual areas V1, V2 and V3 (Dougherty et al., 2003). Taken together with the results of the present study, these observations support the proposition that the amplitude of the evoked EEG gamma-band response is positively related to stimulus size, and probably reflects the size-dependent activation of cortical areas in retinotopic visual cortices (Busch et al., 2004; Hoogenboom et al., 2006).

Our results extend this observation because greater stimuli also led to an increase in inter-trial phase-stability that may be directly linked to higher synchronization of feed-forward and feedback processing in early visual regions. It is generally assumed that high spectral power implies a substantial number of neural units to be active simultaneously (Srinivasan et al., 1999; Varela et al., 2001). However, the ability to synchronize fast frequency responses may reflect processing abilities that are not identical to those indexed by power values (Yordanova et al., 2002). For example, recent models of visual processing highlight the importance of rapid feedback signals in early vision (Bullier, 2001; Körner et al., 1999; Lamme and Roelfsema, 2000). Concerning evoked gammaband responses, the "match-and-utilization model" (MUM) by Herrmann and colleagues (Herrmann et al., 2004) suggests that visual input into early extrastriate cortex leads to rapid activation of higher visual areas in occipito-temporal cortex (e.g., V4), where perceptual memory representations are stored in the form of enhanced synaptic connections between and within visual areas. Following this proposition, input that matches stored perceptual representations - which is the case for the simple geometric shapes used in the present study - would result in rapid local feedback signals, which in turn promote enhanced gamma activity in the network. According to this line of reasoning, larger stimuli do engage more neurons not only because they cover larger parts of the retina. In addition, larger stimuli may also trigger stronger feedback from higher visual areas, resulting in faster synchronization of sensory feed-forward information with feedback as evidenced in increased phase-stability of gamma oscillations across trials (Fründ and Herrmann, 2007).

Nevertheless, the age-differential patterns for evoked gamma power and measures of inter-trial phase-stability point to slightly different processes tagged by these indicators. Starting with children, we now address the implications of these findings for neuronal coding in early visual processing across the lifespan. 
4.2. ERP and evoked gamma-band responses in children: immaturity of synchronization-enhancing mechanisms

Relative to younger adults, children showed a more shallow increase in evoked gamma power and phase-stability with increasing stimulus size. Given the purported relation between stimulus size on neuronal processing outlined above, this difference may reflect delayed or less synchronized local feedback signals. This relative lack of synchronization may reflect age-associated differences in myelination (Giedd, 2004; Paus, 2005; Paus et al., 2001; Tsuneishi and Casaer, 1997) facilitating the generation of synchronous neuronal activity.

Along similar lines, throughout development, and at least until late childhood, cycles of increases in grey matter density, that is, an increase in nerve cells, axonal arborization and synaptic links, alternate with the gradual elimination or pruning of superfluous neurons and connections, probably reflecting mechanisms of fine tuning that are partly under environmental influence (Giedd et al., 1999; Huttenlocher, 1994; Thatcher, 1992, 1994). In early visual areas, this cyclic pattern of growth and pruning occurs at very early ages with a rapid burst of synapse formation in the first postnatal months and a peak of synaptic density, which exceeds $150 \%$ of the adult level, between four and twelve months. At the end of the first year, synaptic density starts to decrease and gradually reaches adult levels in middle childhood (Huttenlocher and de Courten, 1987; Huttenlocher et al., 1982). Therefore, we suggest that the higher P1/N1 peak amplitudes for children observed in the present study reflect, at least to some degree, higher synaptic densities in visual areas relative to younger and older adults. The increased amplitudes observed in the present study may thereby result from transient connections between neurons that were not yet shaped by maturational and learning processes (Lippe et al., 2007).

Efficient neuromodulation improves the temporal precision of neuronal synchronization (for recent reviews, see Buzsaki et al., 2007; Ito and Schumann, 2008). Most investigations addressing the effects of early developmental changes in neuromodulation on neuronal synchronization were carried out in animal models and primarily refer to intrauterine and early postnatal phases of development (Ben-Ari et al., 2004; Le Van Quyen et al., 2006). Recent studies using rat and primate models also report protracted development of neurotransmitter systems well into adolescence (Cruz et al., 2003; Hashimoto et al., in press). For instance, work with rodents indicates that the dopaminergic modulation of interneurons matures particularly late in the course of development (Tseng and O'Donnell, 2007). Given the importance of inhibitory interneuron networks for the generation of gamma rhythms (e.g., Bartos et al., 2007; Whittington and Traub, 2003), it appears plausible to propose that age-graded changes in neurotransmitter systems (e.g., GABA, dopamine) influence the tuning of neuronal responses in children. Future work needs to address this proposition more directly. For this purpose, the extent to which age differences in markers of stimulus-induced neuronal synchronization as observed with human scalp EEG can be taken to reflect maturational changes in neurotransmitter systems requires further study (e.g., Whittington, 2008).

In addition, it has to be noted that the observed age differences between children and younger adults may be influenced by maturational differences in factors like skull thickness, brain size, and brain geometry (e.g., Frodl et al., 2001). However, as reported by Lippe et al. (2007), ERP amplitudes (i.e., P100) are not monotonously decreasing as a function of age in the age period from 27 days to 5.5 years, and they are not always larger than the amplitudes of young adults, as would be expected on the basis of agegraded differences in skull thickness. While we cannot exclude the possible contribution of additional factors, it seems unlikely that age differences in skull thickness can account for the diversity of findings observed in the present and related studies (for similar arguments concerning maturational changes in brain size and geometry, see Segalowitz and Davies, 2004).

Taken together, reliable synchronous gamma oscillations can be observed in children around $\sim 11$ years. However, compared to adults, the synchronization of neuronal responses to incoming stimuli appears less responsive to changes in stimulus size. In conclusion, the present results suggest that the visual system in children shows higher variability in neuronal stimulus processing (Yordanova and Kolev, 1996), probably related to higher prevalence of non-functional/not integrated neurons and reduced guidance by feedback from higher-order visual areas (Desimone and Duncan, 1995; Herrmann et al., 2004).

\subsection{Evoked gamma-band responses of early visual processing in older adults: sparse representations and temporal coding}

Older adults' evoked gamma power was reduced relative to younger adults for large stimuli $\left(8^{\circ}\right)$ despite equal ERP P1/N1 amplitude, indicating that gamma-band activity is a highly sensitive marker for alterations in the neuronal architecture (Busch et al., 2004). However, comparing the gamma-band responses of older adults to younger adults leads to a radically different picture than comparing children to younger adults. Older adults showed lower gains in evoked power changes with stimulus size, but their inter-trial phase-stability was similar to that of younger adults for intermediate stimuli $\left(4^{\circ}\right)$ and even larger for small stimuli $\left(2^{\circ}\right)$. The finding of relatively preserved inter-trial phase-stability for small- and medium-sized stimuli was somehow unexpected as recent empirical findings and theoretical considerations support the notion that neuronal noise increases with advancing adult age (Li et al., 2001, 2006; MacDonald et al, 2006a,b). Neurocomputational simulations, for example, suggest that aging-related reductions in dopaminergic neuromodulation (as modeled by the slope of the activation function) reduce the sensitivity of model neurons to changes in input variations (Li et al., 2000, 2001, 2006), resulting in less distinct (i.e., dedifferentiated) activation patterns for different stimuli.

In line with these considerations, an earlier study by Böttger and colleagues (Böttger et al., 2002) observed reduced evoked gamma-band activity in response to Kanizsa- and non-Kanizsa figures in a group of participants with a mean age of about 48 years compared to a group of younger adults aged 36 years on average. The authors concluded that the reduced evoked power may result from the difficulty to synchronize processing to the stimuli. As the older participants in our age group exhibited similar and even higher levels of phase-locking as the younger ones for stimuli up to $4^{\circ}$, despite being considerably older than the group studied by Böttger and colleagues, the explanation put forward by Böttger et al. (2002) is not fully consistent with the present results.

Given that the evoked fraction of oscillatory EEG activity is derived from a wavelet transformation of the ERP, it indeed reflects to a large part synchronized activity. However, despite pure phaselocking, power measures are also influenced by the amplitude of oscillations, which in the case of EEG is also affected by the neuronal units active under a given electrode (Srinivasan et al., 1999; Varela et al., 2001). In the present study, all the participants in the group of older adults were at least 70 years of age. Therefore, first signs of senescent reductions in neuronal mass (Sowell et al., 2003), and in neurotransmitter availability are likely (Backman and Farde, 2005; Backman et al., 2006; Li et al., 2001), even in early visual processing areas, which are known to be well preserved in aging (Raz et al., 2005). Furthermore, It has been shown that gamma-band activity is modulated by genetic polymorphisms (Demiralp et al., 2007) and psychiatric disorders (Gallinat et al., 2004; Herrmann and Demiralp, 2005) affecting dopaminergic neu- 
romodulation. Therefore, we suggest that the reduced evoked power changes observed in the older adults group may reflect losses in neuronal mass, reduced dopaminergic neuromodulation, or both, leading to diminished sensitivity to input changes during early visual processing.

Increasing neuronal noise with advancing adult age (Li et al., 2001, 2006; MacDonald et al, 2006a,b) should result in less stable neuronal responses which on a first glance should go along with decreased PLI. The seemingly paradoxical observation of high levels of phase-stability for small stimuli in the group of older adults may be reconcilable if we assume that feedback signals from higher-order visual areas lead to increased inter-trial phase-stability (Fründ and Herrmann, 2007; Herrmann et al., 2004). Along this line, a recent fMRI study reported excessive and more homogeneous activation patterns in higher-order visual areas, reflecting less differentiated object representations in older adults (Park et al., 2004). It is therefore conceivable that older adults' high levels of phase-stability for smaller stimuli resulted from the additional activation of higher-order visual areas. Possibly, temporal stabilization of neuronal processes in early sensory regions by feedback from higher order areas may compensate for adverse age-related effects like neuronal loss or diminished neuromodulation (e.g., Cabeza, 2002; Reuter-Lorenz and Lustig, 2005). Clearly, further investigations are needed to uncover the exact relation of EEG markers of neuronal synchronization to senescent neurochemical and neuroanatomical changes, and the alleged compensatory adaptations to these changes.

\subsection{Lifespan differences in sensory coding mechanisms}

Compared to adults, children's longer P1 and N1 peak latencies and their lower evoked gamma power and phase-locking are consistent with the hypothesis that fine-tuning of early visual processing circuits is still in progress in middle childhood and that the visual system of children is less able to synchronize processing to stimulus onset. Fine-tuning of visual processing may entail the elimination (pruning) of redundant synapses and the facilitation of inter-areal connectivity (Huttenlocher and Dabholkar, 1997; Thatcher, 1992). In this view, neuronal development may progress towards increasingly sparse representations and higher temporal synchronization leading to more efficient stimulus processing.

This proposition is in line with recent models of neuronal repetition priming (Desimone, 1996; Grill-Spector et al., 2006; Henson, 2003; Wiggs and Martin, 1998), suggesting that the repeated exposure to a given stimulus leads to a more efficient cortical representation - a mechanism termed sharpening. In this regard, the direct comparison of children and older adults is particularly informative. Both groups exhibit comparable levels and increases of evoked gamma power, but they differ in their ability to synchronize processing to stimulus onset (at least for rather small stimuli). This suggests that older adults (but also younger adults) may rely on sparse neuronal representations of the stimuli that are highly synchronized, which indicates more efficient processing (Gruber and Müller, 2005; Rainer et al., 2001). On the other hand, as indexed by lower phase locking and increased ERP latencies, the visual system of children is less entrained by incoming information. Their relatively high ERP peak amplitudes may therefore result from an increased number of neurons engaged in stimulus processing which would indicate less sparse representations. Older adults, by contrast, are likely to have developed sparse representational schemes through experience but senescent reductions in neuronal density and neurotransmitter availability are impeding the fine tuned efficiency of this system. While older adults cannot switch back to an excessive use of neuronal mass, they can only rely on guidance by feedback from higher-order visual areas to counteract the loss of representational power on early visual areas. (cf. Mueller et al., in press, for similar arguments in auditory perception).

\section{Summary and conclusions}

We observed differences and commonalities in ERP, evoked power, and $P L I$ in the early visual processing of children, younger adults, and older adults. Relative to younger adults, children showed lower levels of evoked power and phase locking, whereas older adults showed smaller changes in evoked power with increasing stimulus size but similar and even higher amounts of phase locking, at least for small- and medium-sized visual stimuli. Our findings point to profound changes in the processing of visual information from middle childhood to old age (see also Müller et al., in press). The results of this study therefore defy the notion that older adults fall back to a child-like perceptual representation of sensory events.

\section{Acknowledgements}

This study was supported by the German Research Foundation, DFG Research Unit FOR 448, 'Binding: Functional Architecture, Neuronal Correlates and Ontogenesis'. YLS and MW-B express gratitude to the support by the International Max Planck Research School, The Lifecourse: Evolutionary and Ontogenetic Dynamics (LIFE). We gratefully thank Myriam Sander and Sophie Blumensath as well as all other research assistants of the project for their valuable support during data collection. Additionally, we acknowledge Dr. Christoph Herrmann, Dr. Walter Gruber, Dr. Sascha Tamm, and Dr. Markus Bauer for technical advice and fruitful discussions concerning recording and analysis of gamma-band oscillations. Correspondence and requests for materials should be sent to Markus WerkleBergner, Max Planck Institute for Human Development, Center for Lifespan Psychology, Lentzeallee 94, 14195 Berlin, Germany, werkle@mpib-berlin.mpg.de.

\section{References}

Backman L, Farde L. The role of dopamine systems in cognitive aging. In: Cabeza R, Nyberg L, Park D, editors. Cognitive neuroscience of aging: linking cognitive and cerebral aging. New York: Oxford University Press; 2005. p. 58-84.

Backman L, Nyberg L, Lindenberger U, Li SC, Farde L. The correlative triad among aging, dopamine, and cognition: current status and future prospects. Neurosci Biobehav Rev 2006;30(6):791-807.

Ballard DH, Hinton GE, Sejnowski TJ. Parallel visual computation. Nature 1983;306(5938):21-6.

Baltes PB, Lindenberger U. Emergence of a powerful connection between sensory and cognitive functions across the adult life span: a new window to the study of cognitive aging? Psychol Aging 1997;12(1):12-21.

Baltes PB, Reese HW, Nesselroade JR. Life-span developmental psychology: introduction to research methods. Monterey, CA: Brooks-Cole Publishing; 1977.

Baltes PB, Reuter-Lorenz P, Röseler F, editors. Lifespan development and the brain: the perspective of biocultural co-constructivism. New York: Cambridge University Press; 2006.

Baltes PB, Staudinger UM, Lindenberger U. Lifespan psychology: theory and application to intellectual functioning. Annu Rev Psychol 1999;50:471-507.

Barlow HB. Single units and sensation: a neuron doctrine for perceptual psychology? Perception 1972;1(4):371-94.

Bartos M, Vida I, Jonas P. Synaptic mechanisms of synchronized gamma oscillations in inhibitory interneuron networks. Nat Rev Neurosci 2007;8:45-56.

Bauer M, Oostenveld R, Peeters M, Fries P. Tactile spatial attention enhances gamma-band activity in somatosensory cortex and reduces low-frequency activity in parieto-occipital areas. J Neurosci 2006;26(2):490-501.

Ben-Ari Y, Khalilov I, Represa A, Gozlan H. Interneurons set the tune of developing networks. Trends Neurosci. 2004;27:422-7.

Bi GQ Poo MM. Synaptic modifications in cultured hippocampal neurons: dependence on spike timing, synaptic strength, and postsynaptic cell type. J Neurosci 1998;18(24):10464-72.

Böttger D, Herrmann CS, von Cramon DY. Amplitude differences of evoked alpha and gamma oscillations in two different age groups. Int J Psychophysiol 2002;45(3):245-51.

Bullier J. Integrated model of visual processing. Brain Res Brain Res Rev 2001;36(23):96-107. 
Busch NA, Debener S, Kranczioch C, Engel AK, Herrmann CS. Size matters: effects of stimulus size, duration and eccentricity on the visual gamma-band response. Clin Neurophysiol 2004;115(8):1810-20.

Busch NA, Herrmann CS, Müller MM, Lenz D, Gruber T. A cross-laboratory study of event-related gamma activity in a standard object recognition paradigm. Neuroimage 2006;33(4):1169-77.

Buzsaki G, Kaila K, Raichle M. Inhibition and brain work. Neuron 2007;56:771-83.

Cabeza R. Hemispheric asymmetry reduction in older adults: the HAROLD model Psychol Aging 2002;17(1):85-100.

Cabeza R, Nyberg L, Park D, editors. Cognitive neuroscience of aging: linking cognitive and cerebral aging. New York: Oxford University Press; 2005.

Celesia GG. Visual evoked potentials and electroretinograms. In: Niedermeyer E Lopes Da Silva F, editors. Electroencephalography: basic principles, clinical applications and related fields. Baltimore: Williams and Wilkins; 1993. p. 911-36.

Craik FIM, Bialystok E. Cognition through the lifespan: mechanisms of change. Trends Cogn Sci 2006;10(3):131-8.

Cruz DA, Eggan SM, Lewis DA. Postnatal development of pre- and postsynaptic GABA markers at chandelier cell connections with pyramidal neurons in monkey prefrontal cortex. J Comp Neurol 2003;465:385-400.

Csibra G, Davis G, Spratling MW, Johnson MH. Gamma oscillations and object processing in the infant brain. Science 2000;290(5496):1582-5.

D'Esposito M, Deouell L, Gazzaley A. Alterations in the bold FMRI signal with ageing and disease: a challenge for neuroimaging. Nat Rev Neurosc 2003;4(11):863-72.

Delorme A, Sejnowski T, Makeig S. Enhanced detection of artifacts in EEG data using higher-order statistics and independent component analysis. Neuroimage 2007;34(4):1443-9.

Demiralp T, Herrmann CS, Erdal ME, Ergenoglu T, Keskin YH, Ergen M, et al. DRD4 and DAT1 polymorphisms modulate human gamma band responses. Cereb Cortex 2007;17(5):1007-19.

Desimone R. Neural mechanisms for visual memory and their role in attention. Proc Natl Acad Sci USA 1996;93(24):13494-9.

Desimone R, Duncan J. Neural mechanisms of selective visual attention. Annu Rev Neurosci 1995;18:193-222.

Dougherty RF, Koch VM, Brewer AA, Fischer B, Modersitzki J, Wandell BA. Visua field representations and locations of visual areas $V 1 / 2 / 3$ in human visual cortex. J Vis 2003;3(10):586-98.

Efron B, Tibshirani RJ. An introduction to the bootstrap. New York, NY: Chapman \& Hall; 1993.

Engel AK, Fries P, Singer W. Dynamic predictions: oscillations and synchrony in topdown processing. Nat Rev Neurosci 2001;2(10):704-16.

Engel AK, Konig P, Kreiter AK, Schillen TB, Singer W. Temporal coding in the visua cortex: new vistas on integration in the nervous system. Trends Neurosci 1992;15(6):218-26.

Engel AK, Singer W. Temporal binding and the neural correlates of sensory awareness. Trends Cogn Sci 2001:5(1):16-25.

Farge M. Wavelet transforms and their applications to turbulence. Annu Rev Fluid Mech 1992;24:395-457.

Felleman DJ, Van Essen DC. Distributed hierarchical processing in the primate cerebral cortex. Cereb Cortex 1991;1(1):1-47.

Fisher NI. Statistical analysis of circular data. New York, NY: Cambridge University Press; 1993.

Fries P. A mechanism for cognitive dynamics: neuronal communication through neuronal coherence. Trends Cogn Sci 2005;9(10):474-80.

Frodl T, Meisenzahl EM, Mueller D, Leinsinger G, Juckel G, Hahn K, et al. The effect of the skull on event-related P300. Clin Neurophysiol 2001;112:1773-6.

Fründ I, Herrmann CS. Simulating Evoked Gamma Oscillations of Human EEG in a Network of Spiking Neurons Reveals an Early Mechanism of Memory Matching. AIP Conf Proc 2007;913(1):215-21.

Gallinat J, Winterer G, Herrmann CS, Senkowski D. Reduced oscillatory gammaband responses in unmedicated schizophrenic patients indicate impaired frontal network processing. Clin Neurophysiol 2004;115(8):1863-74.

Garrett HE. A developmental theory of intelligence. Am Psychol 1946;1:372-8.

Gazzaley A, D'Esposito M. BOLD functional MRI and cognitive aging. In: Cabeza R, Nyberg L, Park D, editors. Cognitive neuroscience of aging: linking cognitive and cerebral aging. Oxford: Oxford University Press; 2005

Geigy JR. Wissenschaftliche Tabellen [Scientific Tables]. Basel, Switzerland: J.R. Geigy AG; 1977.

Giedd JN. Structural magnetic resonance imaging of the adolescent brain. Ann NY Acad Sci 2004;1021:77-85.

Giedd JN, Blumenthal J, Jeffries NO, Castellanos FX, Liu H, Zijdenbos A, et al. Brain development during childhood and adolescence. a longitudinal MRI study. Nat Neurosci 1999;2(10):861-3.

Gogtay N, Giedd JN, Lusk L, Hayashi KM, Greenstein D, Vaituzis AC, et al. Dynamic mapping of human cortical development during childhood through early adulthood. Proc Natl Acad Sci USA 2004;101(21):8174-9.

Grill-Spector K, Henson R, Martin A. Repetition and the brain: neural models of stimulus-specific effects. Trends Cogn Sci 2006;10(1):14-23.

Grossmann A, Kronland-Martinet R, Morlet J. Reading and understanding continuous wavelet transforms. In: Combes JM, Grossmann A, Tchamitchian $\mathrm{P}$, editors. Wavelets, time-frequency methods, and phase space. Berlin: Springer; 1989. p. 2-20.

Gruber T, Maess B, Trujillo-Barreto NJ, Müller MM. Sources of synchronized induced gamma band responses during a simple object recognition task: a replication study in human MEG. Brain Res 2008;1196:74-84.
Gruber T, Müller MM. Oscillatory brain activity dissociates between associative stimulus content in a repetition priming task in the human EEG. Cereb Cortex 2005;15(1):109-16

Gruber T, Trujillo-Barreto NJ, Giabbiconi CM, Valdes-Sosa PA, Müller MM. Brain electrical tomography (BET) analysis of induced gamma band responses during a simple object recognition task. Neuroimage 2006;29(3):888-900.

Gruber WR, Klimesch W, Sauseng P, Doppelmayr M. Alpha phase synchronization predicts P1 and N1 latency and amplitude size. Cereb Cortex 2005;15:371-7.

Hashimoto T, Nguyen QL, Rotaru D, Keenan T, Arion D, Beneyto M., et al. Protracted developmental trajectories of $\operatorname{GABA}(\mathrm{A})$ receptor alpha1 and alpha2 subunit expression in primate prefrontal cortex. Biol Psychiatry, in press.

Henson RN. Neuroimaging studies of priming. Prog Neurobiol 2003;70(1):53-81.

Herrmann CS, Demiralp T. Human EEG gamma oscillations in neuropsychiatric disorders. Clin Neurophysiol 2005;116(12):2719-33.

Herrmann CS, Munk MH, Engel AK. Cognitive functions of gamma-band activity: memory match and utilization. Trends Cogn Sci 2004;8(8):347-55.

Hoogenboom N, Schoffelen JM, Oostenveld R, Parkes LM, Fries P. Localizing human visual gamma-band activity in frequency, time and space. Neuroimage 2006;29(3):764-73.

Hullett CR, Levine TR. The overestimation of effect sizes from F values in metaanalysis: the cause and a solution. Commun Monogr 2003;70:52-67.

Huttenlocher PR. Synaptogenesis, synapse elimination, and neural plasticity in human cerebral cortex. In: Nelson CA editor. Threats to optimal development: integrating biological, psychological, and social risk factors. Hillsdale, NJ: Erlbaum; 1994. p. 33-54.

Huttenlocher PR, Dabholkar AS. Regional differences in synaptogenesis in human cerebral cortex. J Comp Neurol 1997;387(2):167-78.

Huttenlocher PR, de Courten C. The development of synapses in striate cortex of man. Hum Neurobiol 1987;6(1):1-9.

Huttenlocher PR, de Courten C, Garey LJ, Van der Loos H. Synaptogenesis in human visual cortex-evidence for synapse elimination during normal development. Neurosci Lett 1982;33(3):247-52.

Ito HT, Schumann EM. Frequency-dependent signal transmission and modulation by neuromodulators. Front. Neurosci. 2008;2(2):138-44. doi:10.3389/ neuro.01.027.2008

Jensen 0 . Maintenance of multiple working memory items by temporal segmentation. Neuroscience 2006;139(1):237-49.

Johnson MK. Functional brain development in humans. Nat Rev Neurosci $2001 ; 2: 475-83$

König P, Engel AK, Singer W. Integrator or coincidence detector? The role of the cortical neuron revisited. Trends Neurosci 1996;19(4):130-7.

Körner E, Gewaltig M, Körner U, Richter A, Rodemann T. A model of computation in neocortical architecture. Neural Netw 1999;12(7-8):989-1005.

Kronland-Martinet R, Morlet J, Grossmann A. Analysis of sound patterns through wavelet transforms. Int J Pattern Recog Artificial Intellig 1987;1:273-302.

Lachaux JP, Rodriguez E, Martinerie J, Varela FJ. Measuring phase synchrony in brain signals. Hum Brain Mapp 1999;8(4):194-208.

Lamme VA, Roelfsema PR. The distinct modes of vision offered by feedforward and recurrent processing. Trends Neurosci 2000;23(11):571-9.

Lehrl S. Mehrfachwahl-Wortschatz-test B [multiple-choice knowledge test-B (MWT-B)]. Erlangen, Germany: Straube; 1977.

Le Van Quyen M, Khalilov I, Ben-Ari Y. The dark side of high-frequency oscillations in the developing brain. Trends Neurosci 2006;29:419-27.

Li S, Brehmer Y, Shing YL, Werkle-Bergner M, Lindenberger U. Neuromodulation of associative and organizational plasticity across the life span: empirical evidence and neurocomputational modeling. Neurosci Biobehav Rev 2006a;30:775-90.

Li S, Lindenberger U, Frensch P. Unifying cognitive aging: from neuromodulation to representation to cognition. Neurocomputing 2000;32:879-90.

Li S, von Oertzen T, Lindenberger U. A neurocomputational model of stochastic resonance and aging. Neurocomputing 2006b;69(13-15):1553-60.

Li SC. Biocultural orchestration of developmental plasticity across levels: the interplay of biology and culture in shaping the mind and behavior across the life span. Psychol Bull 2003;129(2):171-94.

Li SC, Lindenberger U, Hommel B, Aschersleben G, Prinz W, Baltes PB. Transformations in the couplings among intellectual abilities and constituent cognitive processes across the life span. Psychol Sci 2004;15(3):155-63.

Li SC, Lindenberger U, Sikstrom S. Aging cognition: from neuromodulation to representation. Trends Cogn Sci 2001;5(11):479-86.

Lindenberger U, Li S-C, Bäckman L, editors. Methodological and conceptual advances in the study of brain-behavior dynamics: a multivariate lifespan perspective. Neurosci Biobehav Rev 2006:30 [Special Issue].

Lindenberger U, Li S, Lovden M, Schmiedek F. The Center for Lifespan Psychology at the Max Planck Institute for Human Development: overview of conceptual agenda and illustration of research activities. Int. J. Psychol. 2007;42(4):229-42.

Lindenberger U, Mayr U, Kliegl R. Speed and intelligence in old age. Psychol Aging 1993;8(2):207-20.

Lippe S, Roy MS, Perchet C, Lassonde M. Electrophysiological markers of visuocortical development. Cereb Cortex 2007;17(1):100-7.

Littell RC, Stroup WW, Freund RJ. SAS for linear models. 4th ed. Cary, NC: SAS Institute; 2002.

Lisman J. The theta/gamma discrete phase code occurring during the hippocampal phase precession may be a more general brain coding scheme. Hippocampus 2005;15(7):913-22.

MacDonald SW, Hultsch DF, Bunce D. Intraindividual variability in vigilance performance. Does degrading visual stimuli mimic age-related "neural noise"? J Clin Exp Neuropsychol 2006a;28(5):655-75. 
MacDonald SW, Nyberg L, Backman L. Intra-individual variability in behavior: links to brain structure, neurotransmission and neuronal activity. Trends Neurosci $2006 b ; 29(8): 474-80$.

Mardia KV. Statistics of directional data. London, UK: Academic Press; 1972.

Markram H, Lubke J, Frotscher M, Sakmann B. Regulation of synaptic efficacy by coincidence of postsynaptic APs and EPSPs. Science 1997;275(5297):213-5.

Müller V, Gruber W, Klimesch W, Lindenberger U. Lifespan differences in cortical dynamics of auditory perception. Dev Sci, in press.

Nelson CA, Luciana $M$, editors. Handbook of developmental cognitive neuroscience. Cambridge, MA: A Bradford Book; 2001.

Oldfield RC. The assessment and analysis of handedness: the Edinburgh inventory. Neuropsychologia 1971;9(1):97-113.

Palanca BJ, DeAngelis GC. Does neuronal synchrony underlie visual feature grouping? Neuron 2005;46:333-46.

Park DC, Polk TA, Park R, Minear M, Savage A, Smith MR. Aging reduces neural specialization in ventral visual cortex. Proc Natl Acad Sci USA 2004;101(35):13091-5.

Paus T. Mapping brain maturation and cognitive development during adolescence. Trends Cogn Sci 2005;9(2):60-8.

Paus T, Collins DL, Evans AC, Leonard G, Pike B, Zijdenbos A. Maturation of white matter in the human brain: a review of magnetic resonance studies. Brain Res Bull 2001;54(3):255-66.

Rainer G, Augath M, Trinath T, Logothetis NK. Nonmonotonic noise tuning of BOLD fMRI signal to natural images in the visual cortex of the anesthetized monkey. Curr Biol 2001;11(11):846-54.

Raz N, Lindenberger U, Rodrigue KM, Kennedy KM, Head D, Williamson A et al Regional brain changes in aging healthy adults: general trends, individual differences and modifiers. Cereb Cortex 2005;15:1676-89.

Reuter-Lorenz PA, Lustig C. Brain aging: reorganizing discoveries about the aging mind. Curr Opin Neurobiol 2005;15(2):245-51.

Rosenblum MG, Pikovsky A, Kurths J, Schäfer C, Tass PA. Phase synchronization: from theory to data analysis. In: Moss F, Gielen S, editors. Handbook of biological physics, vol. 4, Neuro-informatics and neural modelling. Amsterdam, NL: Elsevier; 2001. p. 279-321.

Rugg MD, Morcom AM. The relationship between brain activity, cognitive performance, and aging: the case of memory. In: Cabeza R, Nyberg L, Park D, editors. Cognitive neuroscience of aging: linking cognitive and cerebral aging. New York: Oxford University Press; 2005.

Salinas E, Sejnowski TJ. Correlated neuronal activity and the flow of neural information. Nat Rev Neurosci 2001;2(8):539-50.

Shadlen MN, Movshon JA. A critical evaluation of the temporal binding hypothesis. Neuron 1999;24:67-77.

Segalowitz SJ, Davies PL. Charting the maturation of the frontal lobe: an electrophysiolocial strategy. Brain Cogn 2004;55:116-33.

Singer W, Gray CM. Visual feature integration and the temporal correlation hypothesis. Annu Rev Neurosci 1995;18:555-86.

Singer W, Kreiter AK, Engel AK, Fries P, Roelfsema PR, Volgushev M. Precise timing of neuronal discharges within and across cortical areas: implications for synaptic transmission. J Physiol Paris 1996;90(3-4):221-2.

Sowell ER, Peterson BS, Thompson PM, Welcome SE, Henkenius AL, Toga AW. Mapping cortical change across the human life span. Nat Neurosci 2003;6(3):309-15

Srinivasan R, Russell DP, Edelman GM, Tononi G. Increased synchronization of neuromagnetic responses during conscious perception. J Neurosci 1999;19(13):5435-48.
Tallon-Baudry C. Oscillatory synchrony and human visual cognition. J Physiol Paris 2003:97(2-3):355-63.

Tallon-Baudry C, Bertrand O. Oscillatory gamma activity in humans and its role in object representation. Trends Cogn Sci 1999;3(4):151-62.

Tallon-Baudry C, Bertrand O, Delpuech C, Permier J. Oscillatory gamma-band (30$70 \mathrm{~Hz}$ ) activity induced by a visual search task in humans. J Neurosci 1997;17(2):722-34.

Tallon-Baudry C, Bertrand O, Peronnet F, Pernier J. Induced gamma-band activity during the delay of a visual short-term memory task in humans. J Neurosci 1998;18(11):4244-54.

Tass P, Rosenblum M, Weule J, Kurths J, Pikovsky A, Volkmann J, et al. Detection of $n$ : $m$ phase locking from noisy data: application to magnetoencephalography. Phys Rev Lett 1998;81(15):3291-4.

Thatcher RW. Cyclic cortical reorganization during early childhood. Brain Cogn 1992;20:24-50.

Thatcher RW. Cyclic cortical reorganization: origins of human and cognitive development. In: Dawson G, Fischer KW, editors. Human behavior and the developing brain. New York: Guilford Press; 1994. p. 232-66.

Thatcher RW, Krause PJ, Hrybyk M. Cortico-cortical associations and EEG coherence: a two-compartmental model. Electroencephalogr Clin Neurophysiol 1986;64(2):123-43

Tobimatsu S, Celesia GG. Studies of human visual pathophysiology with visual evoked potentials. Clin Neurophysiol 2006;117(7):1414-33.

Treisman A. Solutions to the binding problem: progress through controversy and convergence. Neuron 1999;24(1):105-10. 111-125.

Treisman AM, Gelade G. A feature-integration theory of attention. Cognit Psychol 1980;12(1):97-136.

Tseng KY, O’Donnell P. Dopamine modulation of prefrontal cortical interneurons changes during adolescence. Cereb Cortex 2007;17:1235-40.

Tsuneishi S, Casaer P. Stepwise decrease in VEP latencies and the process of myelination in the human visual pathway. Brain Dev 1997;19(8):547-51.

Tukey JW. Exploratory data analysis. Menlo Park, CA: Addison-Wesley; 1977.

Varela F, Lachaux JP, Rodriguez E, Martinerie J. The brainweb: phase synchronization and large-scale integration. Nat Rev Neurosci 2001;2(4):229-39.

Von der Malsburg C. The correlation theory of brain function (internal Report 81 2). Göttingen: Max Planck Institute for Biophysical Chemistry; 1981.

Wechsler D. The measurement and appraisal of adult intelligence. 4th ed. Baltimore: Williams \& Wilkins; 1958.

Whittington MA, Traub RD. Interneuron diversity series: inhibitory interneurons and network oscillations in vitro. Trends Neurosci 2003;26:676-82.

Whittington MA. Can brain rhythms inform on underlying pathology in schizophrenia? Biol Psychiatry 2008;63:728-9.

Wiggs CL, Martin A. Properties and mechanisms of perceptual priming. Curr Opin Neurobiol 1998;8(2):227-33.

Yordanova J, Kolev V, Heinrich H, Banaschewski T, Woerner W, Rothenberger A Gamma band response in children is related to task-stimulus processing. Neuroreport 2000;11(10):2325-30.

Yordanova J, Kolev V, Heinrich H, Woerner W, Banaschewski T, Rothenberger A Developmental event-related gamma oscillations: effects of auditory attention. Eur J Neurosci 2002;16(11):2214-24.

Yordanova JY, Kolev VN. Developmental changes in the alpha response system. Electroencephalogr Clin Neurophysiol 1996;99(6):527-38.

Zimmer HD, Mecklinger A, Lindenberger $U$, editors. Handbook of binding and memory: perspectives from cognitive neuroscience. Oxford, UK: Oxford University Press; 2006. 